\title{
A Study on Biomedical Waste Management in a Tertiary Care Hospital, Kolkata
}

\author{
Running title: Biomedical Waste Management in a Tertiary Care Hospital \\ Baishakhi Paria ${ }^{1}$, Sunetra Kaviraj Roy ${ }^{2}$, Aritra Ganguly ${ }^{3}$ \\ ${ }^{1}$ Assistant Professor, Dept of Community Medicine, Calcutta National Medical College, Kolkata, West Bengal, India \\ ${ }^{2}$ Assistant Professor, Dept of Community Medicine, Calcutta National Medical College, Kolkata, West Bengal, India. \\ ${ }^{3}$ Intern, Calcutta National Medical College, Kolkata, West Bengal, India
}

\begin{abstract}
Background: The waste generated during the delivery of health care services carries a high potential of infection and injury than any other type of waste. Objectives: To study the system of segregation, collection, transportation and disposal of biomedical wastes. To assess the knowledge and practices about biomedical waste management among the health care providers. Methodologv: A cross sectional hospital based study was done in a tertiary medical college in Kolkata. Internees, nursing staff, laboratory technicians and biomedical waste handlers were interviewed using a pre- designed and pre-tested schedule separately for their knowledge and practices. Secondly observations were made in the above mentioned departments and details were recorded following observational checklists. Results: Regarding biomedical waste management the overall level of awareness, knowledge and practices was found to be highest among the nursing staff followed by internees, laboratory technicians and least among biomedical waste handlers. There were gaps between knowledge and day to day practices overall among the study subjects but was found to be maximum among the internees. Regarding post-exposure prophylaxis it was found that there was lack of correct knowledge and response. Number of needle prick injuries was found to be maximum among the biomedical waste handlers followed by the internees in the past one year. Lastly observational checklists showed loopholes in the administration of proper biomedical waste management. Conclusion: In a nutshell the overall scenario of biomedical waste management is still masked by the shadow of unawareness.
\end{abstract}

Keywords: Biomedical waste, needle prick injuries, health care provider, knowledge

\section{Introduction}

According to Bio-Medical Waste (Management and Handling) Rules 1998 of India, biomedical waste (BMW) means any wastes solid, fluid or liquid waste including its containers and any intermediate product which are generated during the diagnosis, treatment and immunization of human beings or animals or in research activities pertaining thereto or in the production or testing of biologicals ${ }^{1}$. In present scenario, population explosion and advances in medical facilities with the introduction of sophisticated instruments have increased the waste generation per patient in tertiary health care units ${ }^{2}$. The cause mortality data from India and other developing countries show that infectious diseases are the most common cause of deaths ${ }^{3}$. Improper biomedical waste management has the potential to spread infections leading to development of resistant organisms and bringing these resistant hospital organisms to the doorstep of the community. But among all health problems, there is a particular concern with HIV/ AIDS, Hepatitis B and C for which there is a strong evidence of transmission through health care wastes. Though legal provisions (Biomedical Waste Rules 1998) exist to mitigate the impact of hazardous and infectious hospital waste in the community, still these provisions are yet to be fully implemented especially in India where the level of awareness is found to be unsatisfactory in comparison to the global scenario ${ }^{4}$.The absence of proper waste management, lack of awareness about the health hazards from biomedical wastes, insufficient financial and human resources and poor control of waste disposal are the most critical problems connected with health care wastes ${ }^{5}$.The present study is thus necessary not only to assess the knowledge and practice about biomedical waste management among the various health care providers but also to study the system of segregation, collection, transportation and disposal of biomedical wastes in a tertiary care hospital for the essential recommendations and undertakings that should be taken to improve the health conditions and to implement the old saying "Cleanliness is next to Godliness".

\section{Aims and Objectives}

1) To study the system of segregation, collection, transportation and disposal of biomedical wastes.

2) To assess the knowledge and practices about biomedical waste management among the health care providers.

\section{Material and Methods}

It was a cross sectional hospital based study conducted in Calcutta National Medical College and Hospital, in one of the tertiary hospitals in Kolkata.

During the study period, 50 percent of the internees and nursing staffs in the selected departments and all of the laboratory technicians and biomedical waste handlers of those departments who directly dealt with the biomedical wastes were included in the study. Approximately 160 health care providers including 50 internees, 50 nursing staffs, 30 laboratory technicians and 30 biomedical waste handlers were included in the study. The study was chiefly conducted in the following health departments namelyGeneral Medicine, Surgery, Gynae and Obstetrics, 


\section{International Journal of Science and Research (IJSR) \\ ISSN (Online): 2319-7064}

Index Copernicus Value (2015): 78.96 | Impact Factor (2015): 6.391

Orthopedics, Pathology, Bio-chemistry and Microbiology where maximum amount of bio medical wastes are produced, also a significant amount of biomedical wastes are dealt with, in these departments, by the respective healthcare providers.

Data was analyzed in SPSS version 18 and Epi info version 3.2.3 and GraphPad Prism 5. A scoring system was used for better evaluation of the individual knowledge and practices, separately by calculating the mean score of each of the category along with the standard deviation and range. For correct response/ complete answer- score of 2, for partly correct/ incomplete response score 1 and lastly for wrong response or those having no knowledge score of 0 was allotted.

\section{Result}

Table 1 reveals in each ward medical wastes were mixed with common wastes and there were no covered bins, no predefined path in the hospital for the transport of wastes. It was also observed that plastic wastes are not cut before disposal in any wards.

Table 2 shows that $34 \%$ of the internees have correct knowledge regarding whom to report after any injury by sharps while $48 \%$ of nursing staff and $10 \%$ of technician had correct knowledge regarding this. $76 \%$ of the nursing staff have correct knowledge regarding personal protective equipments in biomedical waste handling whereas $66 \%$ of doctors and $43 \%$ of internees had correct knowledge about this issue.

\section{Discussion}

In our study we came across the knowledge, practice, prevalence of needle stick injury among junior doctors, nursing staff, laboratory technicians and biomedical waste handlers in a tertiary care government hospital in Kolkata. According to the observational checklist of biomedical waste management we found many loopholes in the awareness, practices, attitude and administrative controls as vividly revealed in Table no-1. Under the observational checklist part when we looked for the different color coded begs which are supposed to be used for biomedical waste management, we found that there was paucity of these bags in every department. From outpatient department to operation theatres the paucity was quite evident. Not only were the bags deficient in numbers but also there was lack of proper usage of these bags and covered bins as noticed during the survey. We found that the overall knowledge regarding biomedical waste management was highest among the nursing staffs followed by the junior doctors and the laboratory technicians respectively. Regarding practices of biomedical waste collection, handling and disposal, similar scenario was seen as per their knowledge. An important finding was that internees had greater awareness about different health problems alongwith a good perception about different diseases transmitted by biomedical wastes as compared to nursing staff and laboratory technicians. This result is similar to the result of the study carried by Pandit et al at Gujrat ${ }^{4}$. The fact that the knowledge regarding the color coding and waste segregation at a source was found to be better among nursing staff in comparison to the junior doctors has been partly supported by Mathur et al ${ }^{5,6}$, as in their study they stated that the knowledge of both nursing staff and laboratory technicians are found to be better than the junior doctors whereas in our study we found the knowledge of the laboratory technicians was poorer to that of the junior doctors. In contrary Saini et $\mathrm{al}^{7}$ in their study stated that the overall awareness, knowledge regarding biomedical waste management was highest among the junior doctors followed by nursing staff, laboratory technicians and biomedical waste handlers. In this regard they concluded that people with higher education have more awareness about bio medical waste management. But our study revealed a different idea as per knowledge and practices were concerned because here there are no proper training program or educational session regarding biomedical waste management among the junior doctors, laboratory technicians and biomedical waste handlers whereas all the nursing staff have their compulsory training and educational session regarding biomedical waste management in their educational curriculum. Since these educational sessions and training program regarding biomedical waste management is not obligatory in the educational curriculum of the junior doctors they are unaware of the importance of this vital issue and also they do not attend any open training program regarding this issue. The laboratory technicians of our college and hospital also are not motivated enough regarding the awareness of biomedical waste management due to their inadequate training program. In our study we have not compared the knowledge of biomedical waste handlers with the other groups due to their low educational status. It is probably due to lack of knowledge and vocational training in this category that they are lagging behind. This unawareness regarding biohazard and different diseases among the biomedical waste handlers due to improper education was also revealed by Pandit et al in their study at Gujrat ${ }^{4}$. Proper training is the only way for appropriate management of biomedical wastes as supported by Pandit et al in their study at Gujrat .

The gap of knowledge about segregation and color coding bags which has been revealed in our study was also supported by many other studies too. Very high knowledge was seen in a study at Johanesburg hospital by Ramokate and Basu among doctors and nurses ${ }^{9}$. Correct knowledge regarding color coding of biomedical waste was also found to be high among the staffs at Lucknow as shown by the study of Mathur V et al .

Regarding preventive vaccination both knowledge and practices were best among the nursing staff followed by the junior doctors laboratory technicians and lastly biomedical waste handlers who have absolutely no knowledge and practices regarding preventive vaccination.

Lastly as far as post exposure prophylaxis and needle stick injuries are concerned $52 \%$ of both the junior doctors and nursing staff have correct knowledge of what to do immediately after any injury with sharps. Regarding whom to report after a needle prick injury interns as well as nursing staff have much lower percentages of correct response. Study shows that maximum needle stick injury was experienced by the biomedical waste handlers followed by 


\section{International Journal of Science and Research (IJSR) \\ ISSN (Online): 2319-7064}

Index Copernicus Value (2015): 78.96 | Impact Factor (2015): 6.391

the internees in past one year because they have to work with these sharps directly in their daily work. The fact that maximum needle prick injuries occur among the biomedical waste handlers and that none of these injuries were adequately treated due to lack of reporting to seniors, is supported by other study $^{10}$, where they found $67 \%$ of biomedical waste handlers have multiple needle stick injuries in past one year but was unlike the study done by Sharma S et al ${ }^{11}$ in Agra which showed the history of needle stick injury among class 4 waste handlers was only $19 \%$.

To sum up, the present study outlined that the lack of knowledge, practice and awareness are evident among all the study subjects. The gap between knowledge and practices clearly revealed the unawareness among the study subjects and unfortunately it was found to be maximum among the budding doctors. Also, biomedical waste management program cannot be successfully implemented without the willingness devotion and self-motivation of all levels of the health care delivery personnel.

\section{Conclusions}

From the above study we can easily conclude that starting from the very grass root level of administration to the personal awareness of the individual study populations there are many loopholes. There are deficiencies in various aspects of knowledge and practices regarding biomedical waste handling. This deficiency is to be least among the nursing staff and maximum among the biomedical waste handlers who are the prime person of having their duty to segregate and dispose the waste properly .Its very unfortunate that the overall knowledge, practices and awareness of the nursing staff are still quite good with respect to the learned junior doctors. In the future directions of the study, a system of monitoring should be evolved with the intensive training program at regular time intervals for all staff with special emphasis on junior doctors is the call of the day. Information about the risks linked to biomedical waste can be displayed by posters in hospitals giving instructions for segregation. So from our study it was seen that in the field of medical practice, statutory public health guidelines for Biomedical waste management alone cannot achieve the desired goal, if we cannot motivate and monitor with the help of behavior change communication (BCC) and change in mind set in all strata of medical practice, especially in junior doctors who will lead the way in future.

\section{Source of funding: self}

\section{Conflict of interest: Nil}

Work to be attributed to: Dept of Community Medicine, Calcutta National Medical College, West Bengal, India

\section{References}

[1] Sharma AK. Bhopal: Suvidha Law house;1998. BioMedical Waste (Management and handling) Rules.

[2] Radha KV, Kalaivani K, Lavanya R. A case study of Biomedical waste management in hospitals, Global journal of Health Science 2009; 1:82-88.

[3] WHO. World health report. 2002.

[4] Pandit NB, Mehta HK, Kartha GP, Choudhary SK. Management of bio-medical waste: Awareness and practices in a district of Gujrat. Indian J Public Health 2005;49:245-7.

[5] Plianbangchang PH. "A Report on Alternative Treatment and Non -Burn Disposal Practices'; Safe Management of Biomedical Sharps Waste in India.W.H.O. Publication.

[6] Mathur V,Dwivedi S,Hassan MA,Mishra RP.Knowledge, attitude, and practices about biomedical waste management among healthcare personnel:A cross sectional study.Indian JCommunity Med 2011;36:143-5

[7] Saini S, Nagarajan SS, Sarma RK; knowledge, attitude and practices of biomedical waste management amongst staff of a tertiary level hospital in India. Journal of the Academy of Hospital Administration, 2012; 17(2):1-12.

[8] 8.Salelkar S, Motghare DD, Kulkarni MS, Vaz FS. Study of needle stick injuries amonghealth care workers at a tertiary care hospital Indian J Public Health. 2010 ;54(1):18-20

[9] Ramokate T, Basu D. Health care waste management at an academic hospital: Knowledge and practices of doctors and nurses. S Afr Med J. 2009;99:4445.[Pubmed]

[10].Imail IM, Kulkarni AG, Kamble SV, Borker SA, Rekha $\mathrm{R}$, Amruth $\mathrm{M}$; knowledge, attitude and practice about bio-medical waste management among personnel of a tertiary health care institute in Dakshina Kannada, Karnataka. Al Ameen J Med Sci, 2013; 6(4): 376-380

[11] Sharma,S and Chuhan,S.V.Assessment of biomedical waste management in three apex government hospitals of Agra. Journal of Environment Biology,29,159-162

Table 1: Observational Checklist Of Bio-Medical Waste Management Used in different Wards

\begin{tabular}{|c|c|c|c|c|}
\hline Observational Check List & $\begin{array}{c}\text { Medicine } \\
\text { Ward }\end{array}$ & $\begin{array}{c}\text { Surgery } \\
\text { Ward }\end{array}$ & $\begin{array}{c}\text { Gynae \& Obstetrics } \\
\text { Ward }\end{array}$ & $\begin{array}{c}\text { Orthopaedic } \\
\text { Ward }\end{array}$ \\
\hline Use of Needle Cutter for mutilating Sharps & Yes & No & Yes & No \\
\hline Covered Bins & No & Yes & No & Yes \\
\hline Use of freshly prepared bleaching powder solution per day & No & No & No & No \\
\hline Biohazard label is on all bags & Yes & Yes & Yes & No \\
\hline The Plastic Wastes are cut before disposal & No & No & No & No \\
\hline Use of Dedicated Trolly to carry the waste to temporary storage place & Yes & Yes & No & No \\
\hline Transport of waste through Predefined Path & No & No & No & No \\
\hline Labeling of Bags before final Disposal & No & No & Yes & Yes \\
\hline
\end{tabular}




\section{International Journal of Science and Research (IJSR) \\ ISSN (Online): 2319-7064 \\ Index Copernicus Value (2015): 78.96 | Impact Factor (2015): 6.391}

\section{Comment:}

In every wards medical wastes are mixed with general wastes and there are no covered bins in any wards. There are no predefined path in the hospital and college for the transport of wastes

Table 2: Distribution Of Respondents (Doctors, Nurses And Technicians) According To Knowledge Regarding Biomedical Waste Related Issues $(\mathrm{N}=315)$

\begin{tabular}{|l|l|l|l|}
\hline \multirow{2}{*}{ Biomedical waste related issues } & \multicolumn{3}{c|}{ Correct responses } \\
\cline { 2 - 4 } & Doctors(n=50) & Nurses(n=50) & Technicians $(\mathrm{n}=30)$ \\
\hline Disease transmission, PPE, Vaccines (Maximum possible score= 6) & $33(66)$ & $15(50)$ \\
\hline Diseases transmitted by biomedical waste & $40(80)$ & $38(76)$ & $14(47))$ \\
\hline Personnel protective equipments (PPE) & $30(60)$ & $35(70)$ & $13(43)$ \\
\hline Vaccines & $33(66)$ & $5.12 \pm 0.746$ & $4.40 \pm 0.89$ \\
\hline Mean, range, SD & $5.06 \pm 0.652(3-6)$ & \\
\hline Collection, Disposal (Maximum possible score=10) & $43(86)$ & $9(30)$ \\
\hline Sharp & $33(66)$ & $40(80)$ & $14(15)$ \\
\hline Anatomical waste & $28(56)$ & $42(84)$ & $15(50)$ \\
\hline Infectious non sharp waste & $37(74)$ & $21(42)$ & $6(20)$ \\
\hline Pharmaceutical waste & $18(36)$ & $7.56 \pm 1.358(6-10)$ & $4.00 \pm 2.28(0-8)$ \\
\hline Mean, range, SD & $5.88 \pm 1.734(2-10)$ & \\
\hline Needle stick injury related issues(Maximum possible score=4) \\
\hline Reporting after injury by sharps & $26(52)$ & $24(48)$ & $3(10)$ \\
\hline Measures to be taken after sharp injury & $17(34)$ & $26(52)$ & $10(33)$ \\
\hline Mean, range, SD & $2.14 \pm 1.212(0-4)$ & $2.34 \pm 1.423(0-4)$ & $1.17 \pm 1.053(0-4)$ \\
\hline Overall (Maximum possible score=24) & $13.08 \pm 2.530(8-18)$ & $14.98 \pm 2.386(10-18)$ & $9.57 \pm 2.775(5-15)$ \\
\hline Overall Mean, range, SD &
\end{tabular}

Table 3: Practice Score Obtained by the Doctors, Nurses and Technicians $(\mathrm{N}=130)$

\begin{tabular}{|c|c|c|c|}
\hline Scores & Doctors $(\mathrm{n}=50)$ & $\operatorname{Nurses}(\mathrm{n}=50)$ & Technicians $(n=30)$ \\
\hline \multicolumn{4}{|c|}{ PPE, Vaccines (Maximum possible score $=4$ ) } \\
\hline Mean score & 2.26 & 3.32 & 2.20 \\
\hline Range & $0-4$ & $2-4$ & $0-4$ \\
\hline Standard deviation & 1.209 & 0.653 & 1.270 \\
\hline \multicolumn{4}{|c|}{ Collection,disposal (Maximum possible score $=10$ ) } \\
\hline Mean score & 5.12 & 7.36 & 3.80 \\
\hline Range & $2-8$ & $6-10$ & $0-8$ \\
\hline Standard deviation & 1.466 & 1.425 & 2.250 \\
\hline \multicolumn{4}{|c|}{ Practices about PEP after any injury by dispose sharps (Maximum possible score $=10$ ) } \\
\hline Mean score & 1.78 & 0.18 & 2.40 \\
\hline Range & $0-4$ & $1-4$ & $1-4$ \\
\hline Standard deviation & 1.112 & 1.732 & 1.140 \\
\hline \multicolumn{4}{|c|}{ Total practice score(Maximum possible score $=18$ ) } \\
\hline Mean score & 9.16 & 10.86 & 6.40 \\
\hline Range & $6-13$ & $8-17$ & $3-11$ \\
\hline Standard deviation & 1.952 & 1.927 & 2.541 \\
\hline
\end{tabular}

